
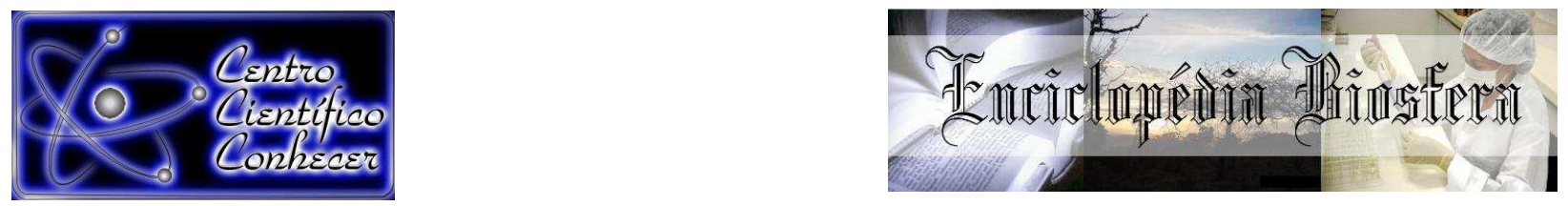

\title{
CARACTERIZAÇÃO QUÍMICA, FÍSICA E MORFOLÓGICA DE SOLOS SOB DIFERENTES SISTEMAS DE CULTIVO EM ASSENTAMENTO DA REFORMA AGRÁRIA
}

Andréa Hentz de Mello"; Gustavo Ferreira de Oliveira²; Everson Kuhn Sbruzzi²; Gilmar Luiz Mumbach²; Elcio Bilibio Bonfada².

${ }^{1}$ Professora Doutora em Ciências do solo da Universidade Federal do Sul e Sudeste do Pará (andreahentz@unifesspa.edu.br) Marabá-PA-Brasil.

${ }^{2}$ Mestrandos do Programa de Pós Graduação em Ciências do Solo da Universidade do Estado de Santa Catarina. Lages-Brasil.

Recebido em: 08/04/2016 - Aprovado em: 30/05/2016 - Publicado em: 20/06/2016 DOI: 10.18677/Enciclopedia_Biosfera_2016_025

\begin{abstract}
RESUMO
O conhecimento e avaliação das características do solo permite o desenvolvimento de diferentes práticas de manejo nos sistemas de produção agropecuários. Sendo assim, este trabalho teve por objetivo caracterizar química, física e morfologicamente os solos em diferentes sistemas de cultivo. Para a realização deste estudo de caso, dois (2) lotes do Projeto de Assentamento (P.A.) Alegria foram avaliados. A caracterização morfológica, física e química dos solos foi realizada em diferentes sistemas de produção destes lotes, de acordo com a importância econômica para a família. O Projeto de Assentamento da Reforma Agrária P.A. Alegria está localizado a margem esquerda do rio Itacaiúnas, próximo à Vila Brejo do Meio no município de Marabá, sudeste do Pará. Foram avaliados atributos morfológicos por meio da abertura de trincheiras, e posterior análise química e física de seis amostras de solo coletadas nestes locais, na profundidade de $0-15 \mathrm{~cm}$, e enviadas ao Laboratório de Análise Química. Foi observado solos característicos da Amazônia, com grandes fragilidades químicas e físicas. Conclui-se que para otimizar os sistemas de cultivos é indispensável a utilização dos solos através de um manejo adequado, em busca de maior sustentabilidade para os seus agroecossistemas.
\end{abstract}

PALAVRAS-CHAVE: Agroecossistemas, desenvolvimento agrícola, manejo do solo.

\section{CHEMICAL, PHYSICAL AND MORPHOLOGICAL SOIL UNDER DIFFERENT CROPPING SYSTEMS IN SETTLEMENT OF LAND REFORM}

\begin{abstract}
Knowledge and assessment of soil characteristics allows the development of different management practices in agricultural production systems. Thus, this study aimed to characterize the chemical, physical and morphological soils in different cropping systems. To carry out this case study, two (2) lots of Settlement Project (P.A.) Joy were evaluated. The morphological, physical and chemical soil was carried out in different production lots of these systems, according to the economic importance for the family. The Settlement Project of Agrarian Reform P.A. Joy is
\end{abstract}


located left bank of Itacaiúnas river, near the Fen of Middle Village in the city of Maraba, southeast of Pará. We evaluated morphological attributes by opening the trenches, and subsequent chemical analysis and physical six soil samples collected at these locations at a depth of $0-15 \mathrm{~cm}$, and sent to the Chemical Analysis Laboratory. It has been observed characteristic soils of the Amazon, with major chemical and physical weaknesses. It is concluded that to optimize cropping systems land use is essential through proper management, seeking greater sustainability for their agro-ecosystems.

KEYWORDS: Agro-ecosystems, development, agricultural soil management.

\section{INTRODUÇÃO}

A utilização do solo de maneira sustentável, respeitando suas aptidões e limitações ao cultivo, é indispensável para a obtenção de sucesso na prática agrícola. Além do uso do solo de maneira a respeitar suas deficiências, é fundamental a adoção de culturas adaptadas à região de cultivo, e sempre que possível utilizando-se de práticas que visem a rotação, sucessão ou consorciação de espécies e sistemas de produção agrícola.

A agricultura realizada na região Amazônica em grande parte é praticada pela mão de obra familiar, utilizando na maioria das vezes o sistema de corte e queima, pratica essa que utiliza extensivamente os recursos do solo com inevitável esgotamento e consequente abandono da área (COSTA et al., 2014). A derrubada e queima de florestas gera sérios impactos negativos ao ecossistema como um todo, sendo necessários cerca de 25 a 30 anos para que sua vegetação seja reconstituída e a fertilidade desse solo atinja níveis similares aos encontrados quando o sistema encontrava-se em equilíbrio (KER et al., 2012).

Diferentes atributos físicos, químicos e biológicos afetam diretamente 0 crescimento e desenvolvimento de plantas e a diversidade de microrganismos do solo. Alterações no solo que afetam atributos ligados a estrutura do solo podem

gerar limitações quanto a fertilidade e, por consequência, gerar perdas no rendimento (GOMIDE et al., 2011).

Um dos principais atributos ligados a qualidade do solo, e que afeta diretamente os seus parâmetros químicos, físicos e biológicos é a matéria orgânica. Armazenamento de água no solo, estrutura, fertilidade química são alguns dos vários parâmetros afetados pela matéria orgânica do solo (MOS). A redução da fertilidade em certos ambientes agrícolas é fruto da redução do estoque de MOS (GOMIDE et al., 2011). Os microrganismos também são importantes neste processo, pois produzem substâncias que podem atuar como agentes estabilizadores, como por exemplo as hifas dos fungos micorrízicos arbusculares, que juntamente com pequenas raízes funcionam como uma rede envolvendo os agregados do solo (HENTZ et al., 2011).

Uma etapa básica no planejamento conservacionista de propriedades rurais é a classificação do solo para sua devida aptidão agrícola. Essa classificação é baseada na interpretação das características do solo e agrupa as diferentes glebas em classes de aptidão de uso agrícola. Para cada classe é indicado o tipo de exploração mais adequado, bem como as práticas de manejo e conservação do solo, necessárias para a manutenção ou elevação da produtividade agrícola, sem causar degradação do solo e do ambiente (EMBRAPA, 2013). 
A morfologia do solo também é amplamente utilizada para avaliação do solo em relação ao desenvolvimento de plantas no movimento de água e solutos através do perfil, na resposta a determinados manejos, na sua resistência a degradação pelos processos erosivos e também suporte de obras de engenharia. Estas características, determinadas no campo, juntamente com outras características físicas e químicas determinadas em laboratório permitem ao técnico um julgamento adequado sobre sua melhor utilização (SANTOS et al., 2015).

O sistema de cultivo define-se pelas práticas de manejo associadas às espécies vegetais. Num âmbito mais amplo tem-se os sistemas de produção, que caracterizam-se pelo conjunto de sistemas de cultivo dentro de uma propriedade rural. Esses sistemas podem ser mais ou menos intensificados e/ou diversificados, e assim afetando a qualidade do solo (HIRAKURI et al., 2012). Sistemas que priorizam uma maior diversidade vegetal, bem como uma atuação mais conservacionista do solo tendem a melhorar aspectos como sua estrutura e fertilidade.

Uma alternativa que vem ganhando adeptos na região norte do país é a adoção de sistemas de integração com a floresta. São os sistemas agroflorestais que tendem a gerar diversos benefícios ao solo, aumentando a sua biodiversidade. A adoção desses sistemas em áreas degradadas ou que apresentam solos frágeis pode gerar ganhos em qualidade e, consequentemente, bons rendimentos das culturas adotadas. $O$ aumento nos teores de carbono no solo é outro benefício comum quando da adoção desses sistemas (LIMA et al., 2011; ROCHA et al., 2014). Para um bom resultado em termos econômicos, no entanto, cuidado especial deve ser dado à escolha das espécies que serão cultivadas, buscando priorizar aquelas que sejam adaptadas ao local de implantação e que tenham um mercado consumidor garantido.

Posto isto, este trabalho teve por objetivo caracterizar química, física e morfologicamente os solos em diferentes sistemas de cultivo em dois lotes de um assentamento de reforma agrária no estado do Pará.

\section{MATERIAL E MÉTODOS}

Este trabalho foi desenvolvido no Projeto de Assentamento da Reforma Agrária (P.A.) Alegria (0522'07" S, 4922'07' W) no período de julho a agosto de 2015, correspondente ao verão Amazônico. O P.A. Alegria está localizado a margem esquerda do rio Itacaiúnas, próximo à Vila Brejo do Meio no município de Marabá, sudeste do Pará. Compreende uma área de 3.666,56 ha, divididos em 96 lotes comportando 115 famílias, que sobrevivem da produção de bovinos, caprinos ovinos e do cultivo de arroz de sequeiro (Oryza stiva), feijão (Phaseolus vulgaris L.) milho (Zea mays L.) banana (Musa spp) e hortaliças em geral, destacando ainda atividades relacionadas a piscicultura e a extração vegetal de açaí (Euterpe oleracea), (INCRA, 2012). A produção do assentamento é destinada em parte ao consumo dos próprios agricultores e o excedente é vendido no mercado local que complementa a renda familiar dos assentados.

Segundo a classificação de Köppen, o clima local é caracterizado como Tropical chuvoso no clima de Selva Isotérmica (Afi). Pela classificação de Thornthwaite, Marabá se enquadra no clima subúmido com deficiência de água pequena ou nula, com vegetação associada de floresta tropical úmida e evapotranspiração potencial no verão igual a $38 \%$ do total $\left(\mathrm{C}_{2} \mathrm{~A}^{\prime} \mathrm{ra} \mathrm{A}^{\prime}\right)$. Apresenta temperatura média de $28^{\circ} \mathrm{C}$, precipitação anual $1934 \mathrm{~mm}$, com período chuvoso que vai de outubro a maio, durando, geralmente, em média, 187 dias (ALMEIDA, 2007). 
Para a realização deste trabalho dois (2) lotes do P.A. Alegria foram avaliados. A caracterização morfológica dos solos foi realizada em diferentes sistemas de produção destes lotes, de acordo com a sua importância para a família.

Os lotes estudados foram: 1) Lote da vicinal 1 número 86 (Figura 1), que possui área estimada de 18 hectares (ha), dos quais 1,5 ha correspondem ao cultivo de mandioca $(\mathrm{CM}), 2$ ha à área de floresta secundária $(\mathrm{FS})$ e 14,5 ha à área de pastagens (AP).

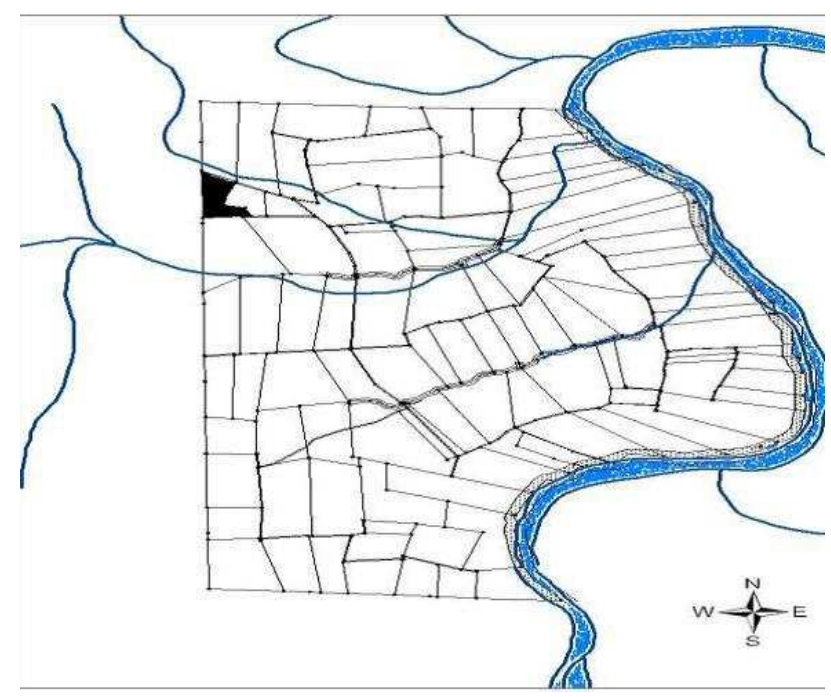

FIGURA 1 Localização do lote 86

Fonte: MIRANDA \& ARAÚJO (2009)

O lote 2: Sitio São Francisco, número 61 (Figura 2), vicinal 11, com uma área de 42.8497 ha. Os agroecossistemas estudados foram a área de pastagem (AP), floresta secundária (FS) e quintal agroflorestal (QA).

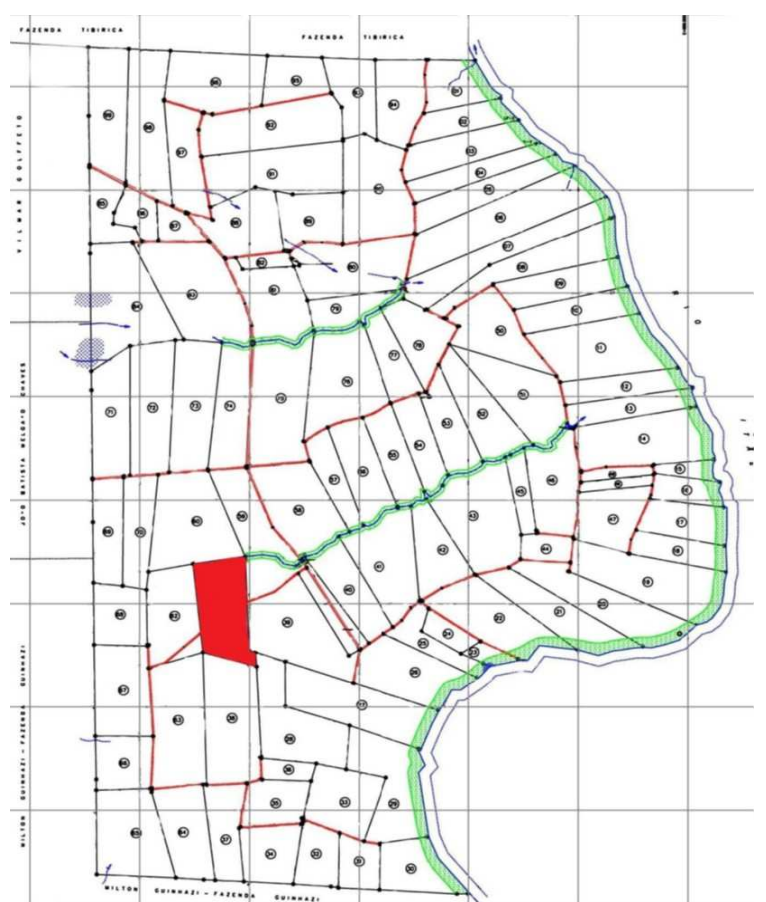

FIGURA 2 Localização do lote 61

Fonte: INCRA (2012). 
No quadro 1 estão apresentados os diferentes sistemas de cultivo avaliados nos dois lotes em estudo.

QUADRO 1 Lotes e respectivos sistemas de produção avaliados no P.A. Alegria Marabá - PA

\begin{tabular}{cc}
\hline Lotes & Sistemas de produção \\
\hline \multirow{2}{*}{ Lote 1} & 1 - Floresta \\
& 1 - Pastagem \\
1 - Mandioca \\
\hline \multirow{2}{*}{ Lote 2} & 2 - Floresta \\
& 2 - Pastagem \\
2 - Agrofloresta \\
\hline
\end{tabular}

Para a realização das análises morfológicas dos solos em todos os sistemas de produção dos lotes selecionados, trincheiras foram abertas para a caracterização dos perfis, de acordo com a metodologia descrita no manual de descrição e coleta de solo no campo (SANTOS et al., 2015). Para a caracterização dos horizontes e camadas dos perfis dos solos, foram avaliadas: a cor (de acordo com a Carta de Munsell), textura, estrutura, consistência, plasticidade, pegajosidade, cerosidade e outros parâmetros que foram julgados importantes para a classificação dos referidos solos. Cabe destacar que apenas no lote 1 foi realizada uma descrição morfológica completa e, desta forma, apenas esta tem seus dados apresentados na sequência do trabalho.

As trincheiras abertas em sua maioria mediram em torno de 1 metro de profundidade. Foram realizadas a separação dos horizontes e camadas observando a variação de cor de cada seção e logo em seguida foram coletadas amostras de solo de cada seção e colocadas em jornais para facilitar a sua caracterização.

Para a análise física e química do solo foram realizadas coletas de seis amostras nas áreas onde foram abertas as trincheiras, na profundidade de $15 \mathrm{~cm}$. As coletas de solo foram feitas de acordo com a metodologia preconizada por SANTOS et al., (2015), constituindo-se de uma área amostral de $100 \mathrm{~m}^{2}$, onde as amostras foram acondicionadas em sacos plásticos para melhor conservação das mesmas. Em seguida foram encaminhadas para 0 Laboratório de Análise Agronômica e Consultoria Fullin Ltda, no Estado do Espírito Santo.

Após a caracterização morfológica de todos os perfis, os dados foram processados, compilados e apresentados na forma de tabela, ressaltando que como este estudo enquadra-se como um "estudo de caso", buscando avaliar parâmetros básicos envolvidos na qualidade do solo em diferentes formas de condução do solo, as coletas não seguiram um padrão experimental, e por isto os resultados apresentados não foram avaliados estatisticamente.

\section{RESULTADOS E DISCUSSÃO}

$\mathrm{Na}$ Tabela 1 podem ser observados os valores da caracterização química nos diferentes sistemas de cultivo, em ambos os lotes avaliados. Apesar de não ter sido realizada análise estatística dos dados, pode-se perceber que o percentual de matéria orgânica é maior na área de floresta, em comparação aos sistemas que sofreram maiores impactos antrópicos. O tipo de cultura e sistema de preparo e 
condução do solo também afetam a qualidade química, física e biológica do solo. De acordo com PEGORARO et al. (2011), o cultivo de espécies arbóreas tende a elevar o teor de carbono total no solo, em comparação a sistemas de cultivo mais intensivo, como as pastagens. Uma das possíveis explicações para isso, segundo os autores, é a maior taxa de deposição de resíduos vegetais sobre o solo, sendo estes muitas vezes mais lignificados $\mathrm{e}$, consequentemente, mais recalcitrantes. $O$ balanço de nutrientes também tende a ser maior nesses ambientes mais equilibrados, devido a maior reciclagem de nutrientes e menores taxas de absorção. Porém vários estudos têm revelado a maior presença de carbono orgânico em solos sobre pastagens em relação a outros sistemas. Segundo QASEM (1992), as gramíneas proporcionam constante aporte de material orgânico ao solo em razão da eficiência fotossintética e do sistema radicular fasciculado, o que pode explicar o aumento da MOS na área de pastagem no lote 2. Além disso, as espécies da família das gramíneas podem aumentar o aporte de carbono em profundidade (VIEIRA et al., 2015).

TABELA 1 Resultados das análises químicas de solo dos diferentes sistemas de cultivo, nos dois lotes estudados. P.A. Alegria - Marabá - PA

\begin{tabular}{|c|c|c|c|c|c|c|c|c|}
\hline \multirow{2}{*}{ Sistema } & \multirow{2}{*}{$\begin{array}{c}\text { pH } \\
\text { (água) }\end{array}$} & \multirow{2}{*}{ MO (\%) } & \multirow{2}{*}{ V (\%) } & \multirow{2}{*}{$\begin{array}{c}P \\
(p p m)\end{array}$} & \multirow{2}{*}{$\begin{array}{c}\text { K } \\
\text { (ppm) }\end{array}$} & $\mathrm{Ca}$ & $\mathbf{M}$ & Al \\
\hline & & & & & & \multicolumn{3}{|c|}{$\mathrm{cmol}_{\mathrm{c}} \mathrm{kg}^{-1}$} \\
\hline 1 - Floresta & 3,8 & 2,4 & 8,3 & 4 & 32 & 0,4 & 0,2 & 2,3 \\
\hline 1 - Pastagem & 5,6 & 2,1 & 40,7 & 4 & 45 & 0,3 & 0,1 & 2,5 \\
\hline 1 - Mandioca & 5,3 & 2,6 & 27,1 & 5 & 49 & 0,4 & 0,2 & 2,3 \\
\hline 2- Floresta & 4,8 & 1,9 & 20,2 & 3 & 44 & 0,8 & 0,1 & 1,0 \\
\hline 2 - Pastagem & 4,3 & 1,7 & 8,6 & 5 & 28 & 0,4 & 0,1 & 1,7 \\
\hline $2-\mathrm{QAF}^{*}$ & 4,6 & 1,4 & 13,5 & 6 & 60 & 0,4 & 0,1 & 1,7 \\
\hline
\end{tabular}

Em relação às características físicas, a argila é considerada a mais importante fração granulométrica do solo, pois além das propriedades físicas condiciona também as propriedades químicas do solo. Assim, os solos argilosos armazenam mais nutrientes e retém elementos tóxicos que podem ser degradados por microrganismos, impedindo ou diminuindo a contaminação do lençol freático (AZEVEDO \& DALMOLIN, 2004).

Os dados da análise física, representados pela granulometria, podem ser observados na Tabela 2.

TABELA 2 Resultados da análise granulométrica de solo dos diferentes sistemas de cultivo, nos dois lotes estudados. P.A. Alegria - Marabá - PA

\begin{tabular}{ccccc}
\hline \multirow{2}{*}{ Sistema } & Areia grossa & Areia fina & Silte & Argila \\
\cline { 2 - 5 } & \multicolumn{4}{c}{$\mathrm{g} \mathrm{kg}^{-1}$} \\
1- Floresta & 348 & 336 & 216 & 100 \\
1 - Pastagem & 468 & 244 & 182 & 140 \\
- Mandioca & 434 & 244 & 182 & 140 \\
\hline $2-$ Floresta & 138 & 200 & 502 & 60 \\
2 - Pastagem & 390 & 202 & 248 & 160 \\
2 - Agrofloresta & 436 & 148 & 256 & 160 \\
\hline
\end{tabular}


A formação dos agregados no solo depende basicamente dos fatores que promovem a aproximação das partículas de areia, silte e argila e dos fatores que irão manter estas partículas unidas contra outras forças que tendem a separá-las. Entre os fatores que promovem a aproximação das partículas destaca-se a floculação das argilas, que é um processo físico-químico dependente do $\mathrm{pH}$ e dos cátions presentes na solução do solo e adsorvidos (AZEVEDO \& DALMOLIN, 2004).

Processos físicos como a desidratação e a pressão exercida pelas raízes também influenciam na formação dos agregados do solo. Os organismos também contribuem para a gênese de agregados. Uma vez formados os agregados é necessário que estes permaneçam estáveis, sendo que entre os principais agentes que dão estabilidade estão os argilominerais, óxidos de ferro e de alumínio e a matéria orgânica.

A textura do solo é um atributo de forte relação com a aptidão do solo ao cultivo. SANTOS et al. (2015) ressaltam que a textura influencia o fluxo e a qualidade da água superficial, subsuperficial e o comportamento químico de nutrientes e elementos tóxicos. A granulometria do solo está ligada ao seu comportamento físico arranjo das partículas (estrutura), oferecendo maior ou menor resistência a degradação por erosão, ao desenvolvimento das plantas, pois tem influência na disponibilidade de nutrientes e água e na penetração das raízes.

A preocupação de uma utilização racional da terra tem proporcionado, nos últimos tempos, uma busca de metodologias adequadas que expressem as possibilidades do uso racional do meio e que representem um aproveitamento equilibrado do ecossistema. Sendo assim, através da análise morfológica do solo, ou seja, da identificação das características físicas pode-se obter informações importantes de interesse agronômico e econômico tais como a fertilidade do solo e seu tempo de formação e manejo.

$\mathrm{Na}$ planície amazônica distinguem-se duas principais unidades geomorfológicas: a terra firme, não inundável, oriunda de formação sedimentária do terciário e as várzeas inundáveis, formadas a partir do depósito de sedimentos do rio Amazonas e dos seus afluentes. Na terra firme, são verificadas boas propriedades físicas, mas de baixa fertilidade natural. Nas florestas primárias, os nutrientes presentes nos solos e na biomassa vegetal fazem parte de um ciclo dinâmico entre o solo e as plantas. Quando a floresta é convertida em sistemas agrícolas, a ciclagem de nutrientes é interrompida e a fertilidade decresce rapidamente (JORDAM, 1989).

Os dados da analise morfológica do lote 1 são apresentados na Tabela 3.

TABELA 3 Caracterização morfológica dos três sistemas de cultivo avaliados no lote 1. P.A. Alegria - Marabá - PA

\begin{tabular}{|c|c|c|c|c|c|c|}
\hline \multirow[b]{2}{*}{ Floresta } & \multirow{2}{*}{$\begin{array}{l}\text { Prof. } \\
\text { (cm) }\end{array}$} & \multirow{2}{*}{$\begin{array}{l}\text { Cor } \\
\text { úmida }\end{array}$} & \multirow{2}{*}{ Textura } & \multirow{2}{*}{ Consistência } & \multicolumn{2}{|c|}{ Estrutura } \\
\hline & & & & & Tipo & Tamanho \\
\hline Seção A & $0-17$ & $\begin{array}{l}5,0 \text { Y } 2 / 2 \\
\text { Preto }\end{array}$ & $\begin{array}{c}\text { Argila } \\
\text { arenosa }\end{array}$ & $\begin{array}{l}\text { Plástico } \\
\text { Lig. Peg. }\end{array}$ & Granular & $\begin{array}{c}\text { Muito } \\
\text { pequeno }\end{array}$ \\
\hline Seção B & $18-38$ & $\begin{array}{c}5,0 \text { Y } 5 / 6 \\
\text { Oliva }\end{array}$ & Argilosa & $\begin{array}{l}\text { Plástico } \\
\text { Pegajoso }\end{array}$ & Granular & Pequeno \\
\hline Seção C & $39-59$ & $\begin{array}{c}2,5 \text { Y 7/6 } \\
\text { Amarelado }\end{array}$ & $\begin{array}{l}\text { Muito } \\
\text { argilosa }\end{array}$ & $\begin{array}{c}\text { Plástico } \\
\text { Pegajoso }\end{array}$ & Granular & Pequeno \\
\hline Seção D & $60-78$ & $\begin{array}{c}10,0 \text { YR } \\
5 / 4 \\
\text { Bruno }\end{array}$ & Argilosa & $\begin{array}{l}\text { Plástico } \\
\text { Pegajoso }\end{array}$ & Subangular & Pequeno \\
\hline
\end{tabular}




\begin{tabular}{|c|c|c|c|c|c|c|}
\hline $\begin{array}{l}\text { Seção E } \\
\text { Seção F }\end{array}$ & $\begin{array}{c}79-107 \\
107- \\
120 \\
\end{array}$ & $\begin{array}{c}5,0 \text { YR } 4 / 6 \\
\text { Bruno } \\
2,5 \text { YR } 3 / 6 \\
\text { Bruno } \\
\end{array}$ & Argilosa & $\begin{array}{l}\text { Lig. plástico } \\
\text { Lig. Peg. } \\
\text { Lig. plástico } \\
\text { Lig. Peg. }\end{array}$ & Laminar & $\begin{array}{c}\text { Pequeno } \\
\text { Muito } \\
\text { pequeno }\end{array}$ \\
\hline \multirow{2}{*}{ Mandioca } & \multirow{2}{*}{$\begin{array}{l}\text { Prof. } \\
\text { (cm) }\end{array}$} & \multirow{2}{*}{$\begin{array}{c}\text { Cor } \\
\text { úmida }\end{array}$} & \multirow{2}{*}{ Textura } & \multirow{2}{*}{ Consistência } & \multicolumn{2}{|c|}{ Estrutura } \\
\hline & & & & & Tipo & Tamanho \\
\hline Seção A & $0-10$ & $\begin{array}{c}2,5 \text { Y 3/1 } \\
\text { Preto }\end{array}$ & $\begin{array}{l}\text { Franco } \\
\text { arenosa }\end{array}$ & $\begin{array}{l}\text { Lig. plástico } \\
\text { Lig. Peg. }\end{array}$ & Granular & Médio \\
\hline Seção B & $11-29$ & $\begin{array}{c}2,5 \text { Y } 5 / 4 \\
\text { Cinza }\end{array}$ & $\begin{array}{l}\text { Franco } \\
\text { argila- } \\
\text { arenosa }\end{array}$ & $\begin{array}{c}\text { Lig. plástico } \\
\text { Lig. Peg. }\end{array}$ & Angular & Grande \\
\hline Seção C & $30-52$ & $\begin{array}{c}10,0 \text { YR } \\
5 / 6 \\
\text { Bruno }\end{array}$ & $\begin{array}{c}\text { Argila } \\
\text { arenosa }\end{array}$ & $\begin{array}{c}\text { Lig. plástico } \\
\text { Pegajoso }\end{array}$ & Subangular & Médio \\
\hline Seção D & $53-83$ & $\begin{array}{c}\text { 7,5 YR 5/6 } \\
\text { Bruno }\end{array}$ & $\begin{array}{c}\text { Argila } \\
\text { arenosa }\end{array}$ & $\begin{array}{l}\text { Plástico } \\
\text { Pegajoso }\end{array}$ & Granular & Médio \\
\hline Seção E & 84-113 & $\begin{array}{c}\text { 5,0 YR } 5 / 4 \\
\text { Bruno }\end{array}$ & Argilc & $\begin{array}{c}\text { Lig. plástico } \\
\text { Lig. Peg. }\end{array}$ & Granular & Pequeno \\
\hline Seç & $\begin{array}{l}114- \\
135\end{array}$ & $\begin{array}{c}2,5 \text { YR } 5 / 4 \\
\text { Bruno }\end{array}$ & $\begin{array}{c}\text { Argila } \\
\text { arenosa }\end{array}$ & $\begin{array}{c}\text { Lig. plástico } \\
\text { Lig. Peg. }\end{array}$ & Granular & Médio \\
\hline \multirow{2}{*}{ Pastagem } & \multirow{2}{*}{$\begin{array}{l}\text { Prof. } \\
(\mathrm{cm})\end{array}$} & \multirow{2}{*}{$\begin{array}{l}\text { Cor } \\
\text { úmida }\end{array}$} & \multirow{2}{*}{ Textura } & \multirow{2}{*}{ Consistência } & \multicolumn{2}{|c|}{ Estrutura } \\
\hline & & & & & Tipo & Tamanho \\
\hline Seç & $0-9$ & $\begin{array}{c}2,5 \mathrm{Y} 3 / 2 \\
\text { Preto }\end{array}$ & Argilosa & $\begin{array}{c}\text { Lig. plástico } \\
\text { Lig. Peg. }\end{array}$ & Granular & Grande \\
\hline Seçã & $10-24$ & $\begin{array}{c}10 \text { YR } 5 / 4 \\
\text { Bruno }\end{array}$ & Argilosa & $\begin{array}{l}\text { Lig. Peg. } \\
\text { Plástico }\end{array}$ & Granular & Médio \\
\hline Seção C & $25-38$ & $\begin{array}{c}5 \text { Y } 5 / 3 \\
\text { Oliva }\end{array}$ & $\begin{array}{l}\text { Franco } \\
\text { arenosa }\end{array}$ & $\begin{array}{l}\text { Não peg. Não } \\
\text { plástico }\end{array}$ & Granular & Pequeno \\
\hline Seção D & $39-49$ & $\begin{array}{c}5 \text { Y 6/6 } \\
\text { Oliva }\end{array}$ & $\begin{array}{c}\text { Argila } \\
\text { arenosa }\end{array}$ & $\begin{array}{l}\text { Não peg. Não } \\
\text { plástico }\end{array}$ & Granular & Médio \\
\hline Seção E & $50-68$ & $\begin{array}{c}2,5 \text { Y 7/4 } \\
\text { Amarelo }\end{array}$ & Argilosa & $\begin{array}{c}\text { Lig. plástico } \\
\text { Lig. Peg. }\end{array}$ & Granular & Médio \\
\hline Seção F & $69-$ & $\begin{array}{c}10 \text { YR 8/4 } \\
\text { Amarelo }\end{array}$ & $\begin{array}{l}\text { Muito } \\
\text { argilosa }\end{array}$ & $\begin{array}{l}\text { Pegajoso } \\
\text { Plástico }\end{array}$ & Subangular & Pequeno \\
\hline Seçã & $\begin{array}{l}101- \\
135\end{array}$ & $\begin{array}{c}2,5 \text { YR 4/8 } \\
\text { Bruno }\end{array}$ & $\begin{array}{c}\text { Muito } \\
\text { argilosa }\end{array}$ & $\begin{array}{l}\text { M. peg. } \\
\text { M. plás. }\end{array}$ & Subangular & Médio \\
\hline
\end{tabular}

Os três perfis no lote 1 apresentaram características texturais diferentes na Seção $A$, onde na área de floresta (AF) foi encontrado argila arenosa, em Cultivo da Mandioca (CM) franco arenosa e em área de pastagem (AP) argilosa. A cor desta seção diferenciou-se no perfil da AF, sendo classificada como preto oliváceo e preto brunado para $\mathrm{CM}$ e $\mathrm{AP}$, com pequena diferenciação de croma. Foi observada grande quantidade de raízes no perfil AF (Figura 3) nas seções $A, B$, que juntas atingiram $38 \mathrm{~cm}$ de profundidade. Nos demais perfis a presença de raízes foi inexpressiva. As cores com tonalidades de bruno foram as mais predominaram nos perfis analisados, variando entre si nas diferenciações de croma, geralmente. $O$ perfil AP apresentou maior quantidade de argila, com destaque nas seções $E, F$ e $G$, 
sendo argilosa em E e muito argilosa nos dois últimos. Em todos os perfis a cor escura na primeira camada indicando a presença de matéria orgânica foi verificada. $\mathrm{Na} A F$, a matéria orgânica presente é oriunda dos restos vegetais. Este material vegetal depositado sobre o solo é denominado de serrapilheira, liteira, manta orgânica ou "litter". Pela ciclagem biogeoquímica, as folhas, ramos, flores, frutos e fragmentos de casca que caem, após sua decomposição, liberam os nutrientes que são reutilizados para o crescimento da própria floresta (VOGEL et al., 2013). As áreas CM e AP apresentam indícios de matéria orgânica no solo, porém nos seus perfis a presença de serrapilheira foi insipiente, estando presente nos solos apenas produto da decomposição da matéria orgânica.

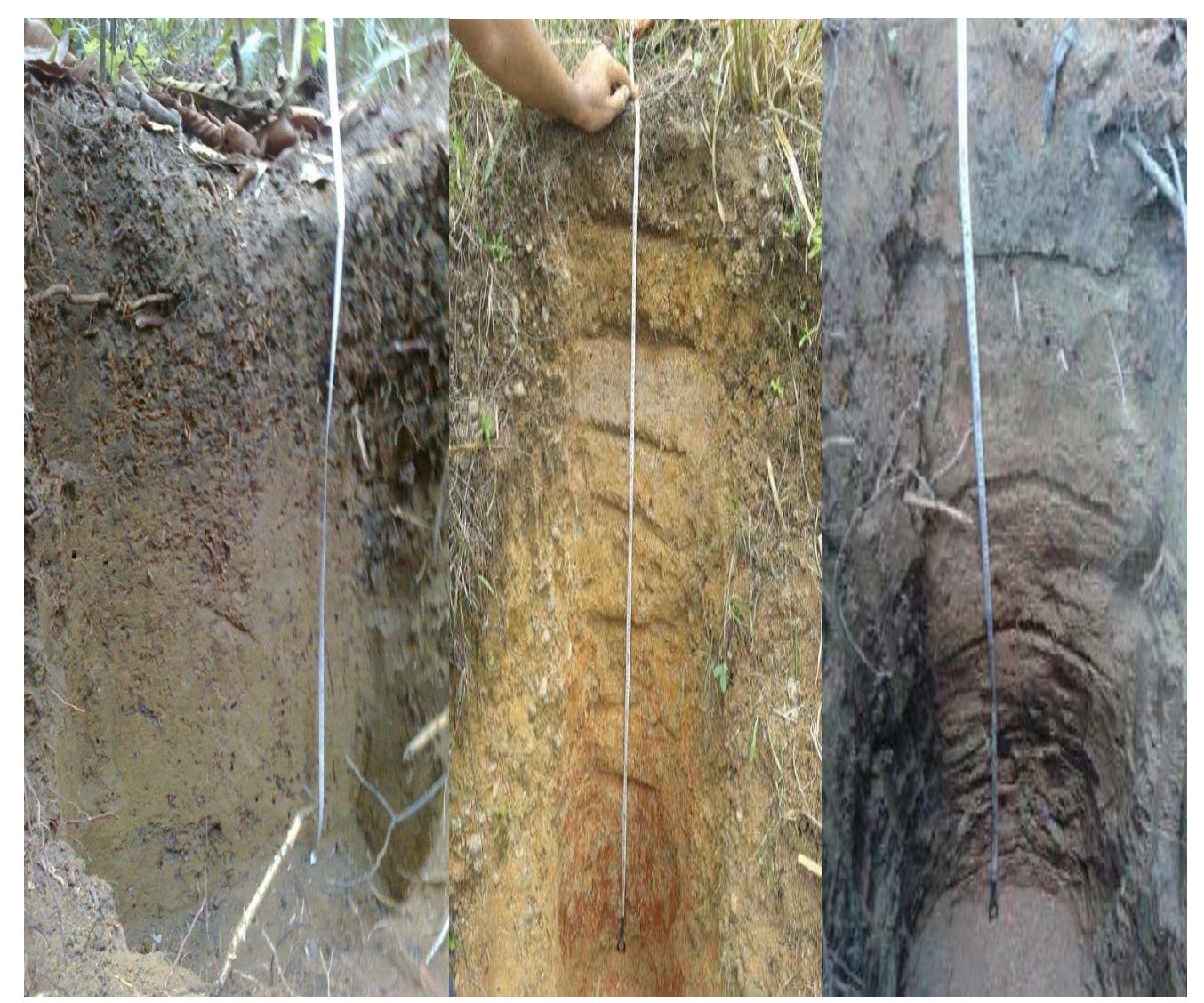

FIGURA 3 Descrição morfológica do Perfil de solo. A) AF; B) AP; C) CM no P.A. Alegria - Marabá - PA

Fonte: Autores.

Nestas áreas, a presença da matéria orgânica se deve aos fatores do relevo que, por estarem em região de vale, recebem parte do material orgânico arrastado pelas águas das chuvas. A vegetação atual na área de CM é apenas com as plantas de cultivo e algumas espontâneas, e em AP pelas gramíneas das pastagens. $\mathrm{Na}$ área do cultivo da mandioca $(\mathrm{CM})$ foi verificada quantidade superior de matéria orgânica humificada incorporada ao solo em relação aos demais agroecossistemas. Os dados de cor confirmam estes resultados, onde ocorreram colorações preto brunado e cinza amarelado nas seções A e B, respectivamente, correspondendo juntas aos primeiros $29 \mathrm{~cm}$ do solo. Os solos deste agroecossistemas são considerados de maior fertilidade, quando comparados aos demais. Isso se deve à incorporação em maior profundidade dos nutrientes, sendo isso demonstrada pela 
sua coloração. No entanto, áreas de cultivo florestal tendem a apresentam maior acumulo de matéria orgânica em relação a outros sistemas de cultivo, como apresentado por Vieira et al. (2015), que encontraram maiores valores de carbono orgânico total em áreas cultivadas com teca (Tectona grandis L. F.) quando comparado a sistemas naturais.

No lote 2, os sistemas de área de pastagem (AP), floresta (AF) e quintal agroflorestal (QAF) também foram estudados. A AF compreende uma área bem significativa na propriedade, e vem sofrendo o processo de sucessão ecológica há aproximadamente 15 anos. Na área existe presença acentuada de cobertura vegetal e de organismos edáficos

O solo da AF apresentou dois horizontes, os quais, o horizonte $A$ apresentou uma espessura de $60 \mathrm{~cm}$ e o horizonte $B, 50 \mathrm{~cm}$. Este solo apresentou grande umidade, principalmente no horizonte $B$ e grande presença de raízes provenientes das plantas que exploravam as partes intermediárias do solo. A cor de ambos os horizontes não variou muito, o Horizonte $A$ apresentou cor cinzento claro e o horizonte $\mathrm{B}$, cinzento. A estrutura foi caracterizada como de blocos angulares $\mathrm{e}$ subangulares. Este tipo de arranjo de partículas caracteriza uma estrutura forte típica de solos que possuem uma infiltração lenta ou muito lenta.

A área de pastagem representa cerca de $60 \%$ do território do Sitio São Francisco. Essa área é de grande importância para a família, uma vez que esta tem sua renda voltada para a venda de leite e laticínios. O horizonte $A$ apresentou uma espessura de $13 \mathrm{~cm}$, com características típicas de área de pasto, com uma coloração cinzenta, provavelmente adquirida pela presença de forragem e do aporte de matéria orgânica, apesar disso esse horizonte superficial apresentou a textura franco argilo arenosa, ou seja, cerca de $70 \%$ de areia. A pegajosidade do horizonte foi pouca e não apresentou plasticidade.

O perfil do solo do quintal agroflorestal apresentou uma profundidade de $1,10 \mathrm{~m}$, o horizonte $A$ do solo do quintal agroflorestal apresentou espessura de $9 \mathrm{~cm}$ e uma cor preta. Essa coloração é explicada pelo fato do material mineral ser escurecido por matéria orgânica. Essa matéria orgânica é explicada pela presença da serrapilheira (Figura 4), que se configura na cobertura que se forma na superfície do solo composta por restos de vegetação, como folhas, arbustos, caules e cascas de frutos em diferentes estágios de decomposição, e fazem parte dela também restos de animais e suas fezes. Esta camada é a principal fonte de nutrientes para ciclagem, enriquecendo o solo e sustentando a vegetação nele presente (TEIXEIRA et al., 2009). Segundo REICHERT (2009) as interpretações das características morfológicas de um solo permitem se fazer inferências à origem do solo, condições de evolução, limitações ao uso e vocação de uso úteis para agricultura familiar e o uso mais sustentável de agroecossistemas. 


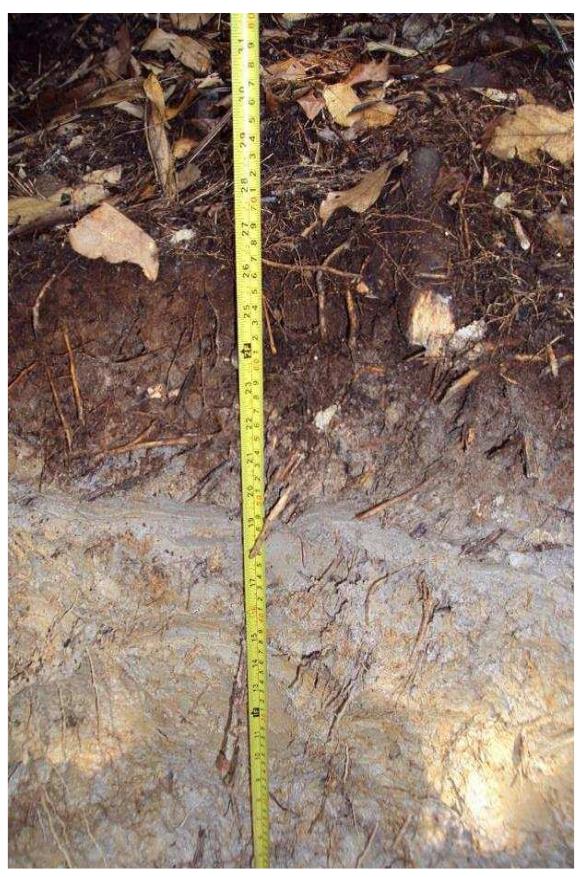

FIGURA 4 Cobertura vegetal da área de Sistema Agroflorestal no P.A Alegria - Marabá Fonte: o próprio autor.

\section{CONCLUSÃO}

Foram observados solos característicos da Amazônia, com fragilidades químicas e físicas. Desta forma, conclui-se que para otimizar os sistemas de cultivos é indispensável a utilização de um manejo adequado, que permita uma visão integrada dos solos, em busca de maior sustentabilidade para os seus agroecossistemas.

\section{REFERÊNCIAS}

ALMEIDA, M.F. Caracterização Agrometeorológica do Município de Marabá/PA. Trabalho de conclusão de Curso - Universidade Federal do Pará -Campus Universitário do Sul e Sudeste do Pará II (CSSP II), Marabá, 2007,62 p.

AZEVEDO, A.C.; DALMOLIN; R. S.D. Solos e ambiente: uma introdução. Editora Pallotti, 2004. $100 \mathrm{p}$.

COSTA, D. L. P; SOUZA, L. C; MELO, N. V; TAKAKI, A. Y; NETO, C. F. O. Caracterização química de solos amazônicos com diferentes coberturas naturais. Enciclopédia Biosfera - Centro Cientifico Conhecer - Goiânia, v.10, n.18; p.885. 2014.

EMBRAPA. Empresa Brasileira de Pesquisa Agropecuária. Sistema Brasileiro de Classificação do Solo. Embrapa Solos. 3 ed. Brasília - DF. 353 p. 2013. 
GOMIDE, P. SILVA, M. SOARES, C. Atributos físicos, químicos e biológicos do solo em ambientes de voçorocas no município de Lavras-MG. R. Bras. Ci. Solo, v. 35, p. 567-577, 2011. Disponível em: < http://dx.doi.org/10.1590/S010006832011000200026>. doi: 10.1590/S0100-06832011000200026

HENTZ, A. M.; SANTOS, E. R.; NUNES, J. S.; KNOECHELMANN, C. M.; BEZERRA, J.; MICHELOTTI F. Produção de mudas de espécies arbóreas inoculadas com fungos micorrízicos para atuar na reabilitação de áreas impactadas pela etração de argila. Revista Agroecossistemas v. 3, n. 1, p. 78-82, Belém, 2011.

HIRAKURI, M. DEBIASI, H. PROCÓPIO, S. FRANCHINI, J. CASTRO, C. Sistemas de produção: conceitos e definições no contexto agrícola. Documentos - Embrapa Soja, n. 335, setembro de 2012.

INCRA. Assentamento Alegria: um exemplo de diversificação agrícola no sul do Pará. 2012. Disponível em: $<$ http://www.incra.gov.br/index.php/noticiassaladeimprensa/ noticias/8474assentamento-alegria-um-exemplo-de-diversificaaao-agracola-no-suldo-para>. Acesso em: 15 dezembro 2012.

JORDAN, C.F. Nutrient cycling in tropical forest ecosystems: principles and their application in management and conservation. John Wiley \& Sons. New York. 190p. 1985.

KER, J. C.; CURI, N.; SCHAEFER, C. E. G. R.; TORRADO, P. V. Fundamentos da Pedologia. Sociedade Brasileira de Ciência do Solo. 1 ed. 343 p. Viçosa - MG, 2012.

LIMA, S. S.; LEITE, L. F. C.; OLIVEIRA, F. C.; COSTA, D. B. Atributos químicos e estoques de carbono e nitrogênio em argissolo vermelho-amarelo sob sistemas agroflorestais e agricultura de corte e queima no norte do Piauí. Revista Árvore, v. 35, n. 1, p. 51-60, 2011. Disponível em: < http://dx.doi.org/10.1590/S010067622011000100006>. doi: 10.1590/S0100-67622011000100006

MIRANDA, J.R. S.; ARAÚJJ, C. S. Plano de recuperação do Projeto de Assentamento Alegria. Cooperativa de Prestação de Serviços - COPSERVIÇOS. Marabá, 2009. 146 p.

PEGORARO, R. SILVA, I. NOVAIS, R. BARROS, N. FONSECA, S. DAMBROZ, C. Estoques de carbono e nitrogênio nas frações da matéria orgânica em Argissolo sob eucalipto e pastagem. Ciência Florestal, v. 21, n. 2, p. 261-273, Santa Maria, 2011.

QASEM, J. R. Nutrient accumulation by weeds and their associated vegetable crops. Journal of Horticultural Science, v.67, n.2, p.189-195, 1992.

REICHERT, J. M. R. Solos Florestais. Apostila Teórica. Centro de Ciências Rurais. Departamento de Solos. Universidade Federal de Santa Maria, Santa Maria RS, 2009. 290p.

ROCHA, G. P.; FERNANDES, L.; CABACINHA, C. D.; LOPES, I. D. P.; RIBEIRO, J. M.; FRAZÃO, L. A.; SAMPAIO, R. A. Caracterização e estoques de carbono de ENCICLOPÉDIA BIOSFERA, Centro Científico Conhecer - Goiânia, v.13 n.23; p. $287 \quad 2016$ 
sistemas agroflorestais no Cerrado de Minas Gerais. Ciência Rural, v. 44, n.7, p. 1197-1203, 2014. Disponível em: <http://dx.doi.org/10.1590/0103-8478cr20130804>. doi: 10.1590/0103-8478cr20130804

SANTOS, R. D; SANTOS, H. G; KER, J. C; ANJOS, L. H C; SHIMZU, S. H. Manual de descrição e coleta de solo no campo. Sociedade Brasileira de Ciências do Solo. 7 ed. 101 p. Viçosa - MG. 2015.

TEIXEIRA, W.G., KERN, D.C.; MADARI, B.E. LIMA, E.M.; WOODS, W.I. As terras Pretas de Índio da Amazônia: Sua Caracterização e Uso deste Conhecimento na Criação de Novas áreas. Manaus: Embrapa Amazônia Ocidentareções de concordância verbal e nominal, bem como inclusão/exclusão de alguns termos para que algumas orações ficassem com melhor compreensão.

VIEIRA, C. R.; WEBER, O. L. S.; JARDINI, D. C. Distribuição do carbono orgânico e do nitrogênio total nas frações granulométricas de um Latossolo sob diferentes tipos de vegetação. Revista de Estudos Ambientais, v. 17, n. 1, p. 43-53, 2015.

VOGEL, H. L. M.; LORENTZ, L. H.; AZEVEDO, J. V. S.; ROTT, L. A. G.; MOTTA, M. S. M. Efeito de borda no estoque de serrapilheira e nutrientes em um fragmento de floresta nativa no Bioma Pampa-RS. Revista Ecologia e Nutrição Florestal, v. 1, n. 1, p. 46-54, Santa Maria, 2013. Disponível em: <http://dx.doi.org/10.5902/2316980X14743 